\title{
The Characteristics of Shoulder Muscles in Archery Athletes
}

\author{
Ri Na Kim ${ }^{3}$ Jin-Hyuck Lee ${ }^{2}$, Seok Ha Hong ${ }^{1}$, Jin Ho Jeon ${ }^{1}$, Woong Kyo Jeong ${ }^{1,2 匹}$ \\ ${ }^{1}$ Department of Orthopaedic Surgery, Korea University College of Medicine, ${ }^{2}$ Sports Medical Center, Korea University Anam Hospital, ${ }^{3}$ Department of Rehabilitation \\ Medicine, Sahmyook Medical Center, Seoul, Korea
}

Background: This study evaluated the shoulder girdle muscle characteristics of elite archery athletes and provides suggestions for archery training programs.

Methods: This study enrolled 15 cases of high level archery athletes ( 7 males, 8 females) and 30 cases of (15 males, 15 females) sex, age-matched, healthy, non-athletic individuals. We measured peak torques of flexion (FL), extension (EX), abduction (ABD), adduction (ADD), external rotation (ER) and internal rotation (IR) of both shoulders at an angular velocity of $30 \% / \mathrm{sec}, 60^{\circ} / \mathrm{sec}$, and $180^{\circ} / \mathrm{sec}$. The peak torques and peak torque ratios of $\mathrm{FL} / \mathrm{EX}, \mathrm{ABD} / \mathrm{ADD}$, and $\mathrm{ER} / \mathrm{IR}$ of the two groups were compared.

Results: The archer group had a greater peak torque of IR and ADD, but only in the left shoulder $(p<0.05)$. In the same group, both shoulders had greater peak torque of EX and lower peak torque of FL. The peak torque ratios of FL/EX of both shoulders were significantly lower in the archer group at all three angular velocities $(p<0.05)$. The peak torque ratios of $A B D / A D D$ were significantly greater in only the left shoulder of the archer group $(p<0.05)$.

Conclusions: The prominent characteristics of the shoulder girdle muscles of an elite archer are stronger adductor muscles of the bow shoulder and stronger extensors of both shoulders, as compared to healthy, non-athletic individuals. These muscle groups of the shoulder probably contribute a major role in maintaining the accuracy and stability during archery shooting. Hence, a training program that selectively enhances the adductor and extensor muscles could prove helpful in enhancing the archery skills of the athlete.

(Clin Shoulder Ellbow 2018;21(3):145-150)

Key Words: Shoulder; Archery; Isokinetic muscle test

\section{Introduction}

Archery is a sport defined by the ability of the competitor to accurately shoot an arrow at a given target in a certain time span. ${ }^{1)}$ Archery is composed of six phases: bow hold, drawing, full draw, aiming, release, and follow-through. From drawing to the release phase, an archer pushes the bow towards the target with one arm extended, while the other arm carries out a rhythmic and dynamic pulling of the bowstring." For a well-balanced performance of these sequential phases, the strength and endurance of both upper extremity muscles, especially the forearm and shoulder girdle muscles, are key factors in achieving a good execution. ${ }^{2}$
A small number of studies have investigated the role of forearm muscles in archery shooting, ${ }^{3-6)}$ and few investigations have researched the shoulder girdle muscles. ${ }^{7,8)}$ Most of these studies focused on the activation patterns of the forearm or shoulder girdle muscles only in terms of electromyographic analysis without any kinesiologic approach, such as isokinetic measurements.

The past few decades has seen increasing studies in isokinetic muscle strength and endurance in various sporting fields such as swimming, baseball, water polo and volleyball ${ }^{9-13)}$; however, to the best of our knowledge, there has been no such specific study in archery.

This study was therefore undertaken to evaluate the shoulder girdle muscle characteristics of elite archery athletes, and study

Received October 30, 2016. Revised May 15, 2018. Accepted May 30, 2018.

Correspondence to: Woong Kyo Jeong

Department of Orthopaedic Surgery, Korea University College of Medicine, 73 Inchon-ro, Seongbuk-gu, Seoul 02841, Korea

Tel: +82-2-920-5924, Fax: +82-2-924-5271, E-mail: drshoulder@korea.ac.kr, ORCID: https://orcid.org/0000-0001-8602-9290

IRB approval: Korea University Anam Hospital (No. ED12154).

Financial support: None. Conflict of interests: None. 
the inherent differences with healthy, non-athletic persons; the data would help to provide suggestions in archery training programs.

\section{Methods}

\section{Subjects}

A total of 7 male and 8 female high level archery athletes were recruited for the study, ranging from 18 to 35 years in age. In order to compare the data derived from the archer group, 30 cases of sex, age-matched healthy, non-athlete volunteers were also recruited. A total of 15 males and 15 females were enrolled as the control group, and the age ranged from 19 to 31 years.

Exclusion criteria for both groups were symptoms such as pain, tenderness or limited range of motion in either shoulder. Subjects who had a previous history of injury, trauma or surgery on either shoulder were also excluded. This study was approved by the Institutional Review Board of Korea University Anam Hospital.

\section{Isokinetic Test}

An isokinetic muscle test machine (Biodex Medical Systems, Shirley, NY, USA) evaluated the variable shoulder movements, and the peak torque of each movement was measured in the following sequence: flexion, extension, abduction, adduction, external rotation, and internal rotation of the right shoulder. The subjects were seated and stabilized with a strap across the chest. Three positions were employed to test each motion. For flexion-extension, the shoulder was positioned to forward flexion and the elbow was extended with neutral forearm rotation. For abduction-adduction, the shoulder was positioned at $90^{\circ}$ abduction and the elbow was extended with neutral forearm rotation. For external rotation-internal rotation, the position applied was $30^{\circ}$ of shoulder abduction with $30^{\circ}$ of scapular plane elevation
( $30^{\circ}$ position). The humeral axis was aligned with the rotational axis of the dynamometer. The elbow was supported at $90^{\circ}$ of flexion, and the forearm was positioned in neutral rotation (Fig. 1).

All tests were performed at $60^{\circ} / \mathrm{sec}, 120 \% \mathrm{sec}$ and $180 \%$ sec for each movement before proceeding to the next one. Movements of both shoulders were measured similarly. In each trial, the subjects were told to complete 15 repetitions; between each trial, there was a 5 minutes resting period. All participants from both groups were monitored to follow the same protocol.

Statistical analysis was conducted using the SPSS 12.0 software (SPSS Inc., Chicago, IL, USA). Mann-Whitney U-test compared the demographic characteristics of the archer and control groups, such as age, height, weight, and body mass index (BMI). The chi-square test was used to match the sex between the two groups. The peak torques and peak torque ratios of flexion/

Table 1. Demographic Characteristics of Archer and Control Group

\begin{tabular}{lccc}
\hline \multicolumn{1}{c}{ Characteristic } & Archer group & Control group & $p$-value \\
\hline Number of case & 15 & 30 & \\
Age $(\mathrm{yr})^{*}$ & $26.20 \pm 4.86$ & $24.37 \pm 2.85$ & 0.110 \\
\hline Sex & & & 0.833 \\
\hline \multicolumn{1}{c}{ Male $^{\dagger}$} & 7 & 15 & \\
Female $^{\dagger}$ & 8 & 15 & \\
Arm dominance $($ right:left $)$ & $15: 0$ & $30: 0$ & \\
\hline Height $(\mathrm{cm})^{*}$ & $173.67 \pm 8.51$ & $169.93 \pm 8.30$ & 0.148 \\
\hline Weight $(\mathrm{kg})^{*}$ & $76.51 \pm 14.47$ & $64.03 \pm 13.69$ & 0.004 \\
\hline Body mass index $\left(\mathrm{kg} / \mathrm{m}^{2}\right)^{*}$ & $25.22 \pm 3.43$ & $22.01 \pm 3.35$ & 0.002 \\
\hline
\end{tabular}

Values are presented as number only or mean \pm standard deviation.

Archer group: high level archery athletes, Control group: sex, age-matched healthy, non-athlete volunteers.

${ }^{*}$ - -values were calculated with Mann-Whitney U-test.

${ }^{\dagger} p$-values were calculated with chi-square test.
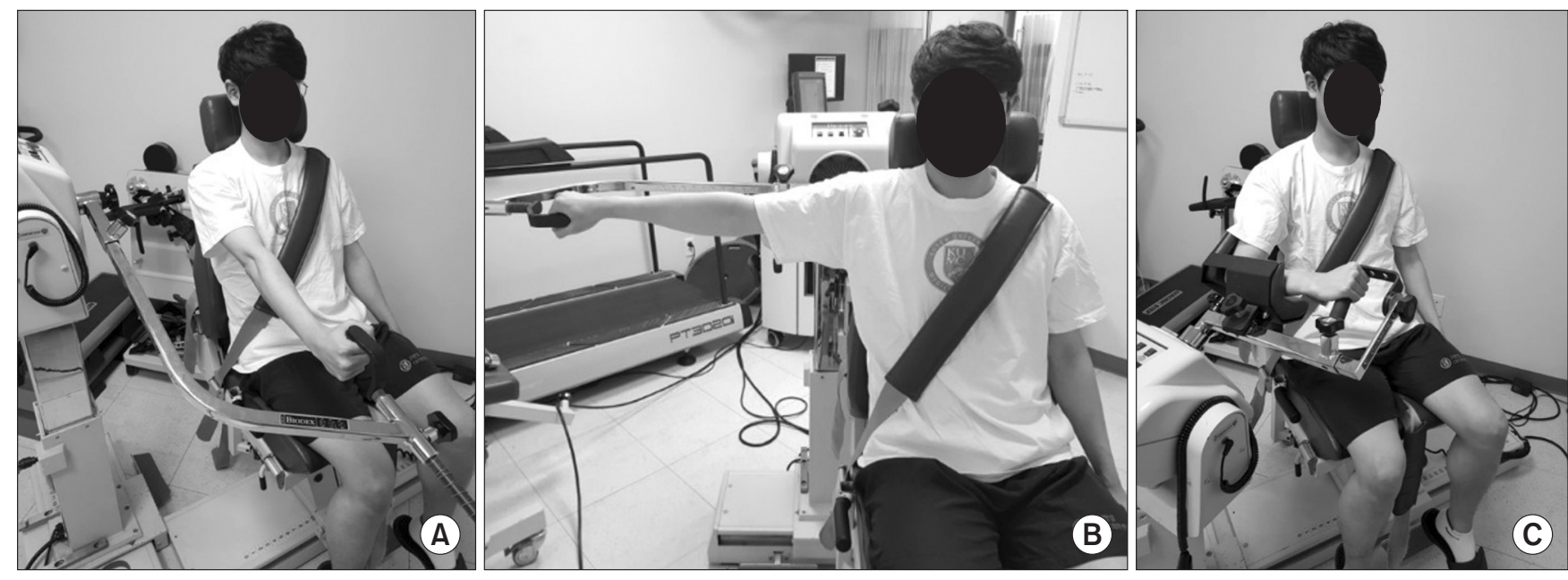

Fig. 1. Isokinetic test position. (A) Position for flexion-extension. (B) Position for abduction-adduction. (C) Position for external rotation-internal rotation. 
extension, abduction/adduction and external rotation/internal rotation between both groups were compared using the MannWhitney U-test. $p$-value less than 0.05 was considered statistically significant.

\section{Results}

A total of 15 national archery athletes ( 7 males, 8 females) were allocated to the archer group and 30 cases healthy, nonathlete volunteers ( 15 males, 15 females) comprised the control group. The mean age of the archer group was $26.20 \pm 4.86$ years (range 18-35 years) and that of the control group was $24.37 \pm 2.85$ years (range 19-31 years). The age and distribution of sex show no statistical difference between the two groups. The demographic characteristics of both groups are summarized in Table 1.

The peak torque of internal rotation and adduction is greater only on the left shoulder of the archer group, except for adduction at $180^{\circ}$ angular velocity $(p<0.05)$. Although no significant differences are observed in other peak torque values between both groups, the flexion peak torques tend to be lower and extension peak torques tend to be greater in the archer group than the control group for both shoulders. Detailed data is presented in Table 2.

A significant decrease is observed in the peak torque ratios of flexion/extension at all angular velocities of both shoulders in the archer group $(p<0.05)$. The peak torque ratios of abduction/ adduction are significantly greater in the archer group only on the left shoulder at $120^{\circ}$ and $180^{\circ}$ angular velocities $(p<0.05)$. The peak torque ratios of external rotation/internal rotation are

Table 2. Comparisons of Peak Torques of Shoulder Girdle Muscles in Archer and Control Group

\begin{tabular}{|c|c|c|c|c|c|c|}
\hline \multirow{2}{*}{ Variable } & \multicolumn{3}{|c|}{ Right (Nm) } & \multicolumn{3}{|c|}{ Left (Nm) } \\
\hline & Archer group & Control group & $p$-value & Archer group & Control group & $p$-value \\
\hline \multicolumn{7}{|l|}{ Flexion } \\
\hline $60 \% \mathrm{sec}$ & $38.29 \pm 19.02$ & $37.59 \pm 17.85$ & 0.96 & $35.46 \pm 16.36$ & $35.48 \pm 18.61$ & 0.97 \\
\hline $120^{\circ} / \mathrm{sec}$ & $34.94 \pm 15.55$ & $35.86 \pm 14.99$ & 0.705 & $31.88 \pm 15.59$ & $35.02 \pm 16.51$ & 0.465 \\
\hline $180^{\circ} / \mathrm{sec}$ & $30.92 \pm 12.40$ & $40.31 \pm 13.67$ & $0.017^{*}$ & $31.14 \pm 14.76$ & $38.07 \pm 12.56$ & 0.096 \\
\hline \multicolumn{7}{|l|}{ Extension } \\
\hline $60 \%$ sec & $71.46 \pm 23.99$ & $61.99 \pm 24.00$ & 0.182 & $69.11 \pm 20.40$ & $56.29 \pm 20.58$ & 0.074 \\
\hline $120^{\circ} / \mathrm{sec}$ & $67.04 \pm 20.32$ & $59.94 \pm 19.49$ & 0.296 & $67.14 \pm 20.80$ & $56.75 \pm 18.11$ & 0.057 \\
\hline $180^{\circ} / \mathrm{sec}$ & $62.21 \pm 18.82$ & $63.65 \pm 14.68$ & 0.571 & $62.49 \pm 18.55$ & $61.90 \pm 13.47$ & 0.512 \\
\hline \multicolumn{7}{|l|}{ Abduction } \\
\hline $60 \% \mathrm{sec}$ & $40.41 \pm 20.57$ & $32.93 \pm 16.20$ & 0.296 & $40.17 \pm 17.63$ & $32.44 \pm 16.31$ & 0.158 \\
\hline $120^{\circ} / \mathrm{sec}$ & $34.85 \pm 18.01$ & $31.74 \pm 13.59$ & 0.743 & $32.79 \pm 16.34$ & $30.91 \pm 13.02$ & 0.98 \\
\hline $180^{\circ} / \mathrm{sec}$ & $34.24 \pm 16.18$ & $36.65 \pm 14.89$ & 0.545 & $30.84 \pm 16.48$ & $35.05 \pm 14.48$ & 0.268 \\
\hline \multicolumn{7}{|l|}{ Adduction } \\
\hline $60 \% \mathrm{sec}$ & $64.29 \pm 24.06$ & $53.52 \pm 18.57$ & 0.118 & $66.69 \pm 20.29$ & $53.16 \pm 19.65$ & $0.038^{*}$ \\
\hline $120^{\circ} / \mathrm{sec}$ & $63.92 \pm 20.47$ & $53.63 \pm 16.68$ & 0.107 & $64.19 \pm 19.72$ & $51.58 \pm 15.99$ & $0.029^{*}$ \\
\hline $180^{\circ} / \mathrm{sec}$ & $59.97 \pm 17.73$ & $61.24 \pm 14.82$ & 0.406 & $61.81 \pm 18.01$ & $58.84 \pm 12.76$ & 0.801 \\
\hline \multicolumn{7}{|c|}{ External rotation } \\
\hline $60 \% \mathrm{sec}$ & $22.43 \pm 10.27$ & $20.63 \pm 9.99$ & 0.531 & $20.81 \pm 8.73$ & $17.77 \pm 9.55$ & 0.163 \\
\hline $120^{\circ} / \mathrm{sec}$ & $20.56 \pm 9.26$ & $19.26 \pm 8.73$ & 0.745 & $19.08 \pm 7.40$ & $16.75 \pm 7.62$ & 0.238 \\
\hline $180^{\circ} / \mathrm{sec}$ & $19.69 \pm 9.01$ & $20.45 \pm 8.21$ & 0.596 & $17.18 \pm 6.60^{*}$ & $18.12 \pm 7.69$ & 0.763 \\
\hline \multicolumn{7}{|c|}{ Internal rotation } \\
\hline $60^{\circ} / \mathrm{sec}$ & $38.20 \pm 13.20$ & $32.25 \pm 12.35$ & 0.132 & $39.76 \pm 9.89$ & $29.89 \pm 11.75$ & $0.006^{*}$ \\
\hline $120^{\circ} / \mathrm{sec}$ & $35.98 \pm 10.88$ & $31.08 \pm 11.18$ & 0.135 & $37.99 \pm 7.17$ & $28.93 \pm 9.75$ & $0.003^{*}$ \\
\hline $180^{\circ} / \mathrm{sec}$ & $35.54 \pm 11.48$ & $31.81 \pm 9.87$ & 0.329 & $36.19 \pm 7.67$ & $30.23 \pm 9.37$ & $0.028^{*}$ \\
\hline
\end{tabular}

Values are presented as mean \pm standard deviation.

Nm: Newton meter, Archer group: high level archery athletes, Control group: sex, age-matched healthy, non-athlete volunteers.

${ }^{*} p$-values were calculated with Mann-Whitney U-test. 
significantly greater only at $180^{\circ}$ angular velocity in the left shoulder of the archer group $(p<0.05)$. Detailed data is presented in Table 3.

\section{Discussion}

An important finding of this study is that archery athletes have greater internal rotation and adduction peak torque of the left shoulder, as compared to non-athletic individuals. Although there is no statistical significance, the extension peak torque of both shoulders is also greater. The abduction/adduction ratio of the left shoulder and the flexion/extension ratio of both shoulders are found to be lower in archery athletes.

In terms of a force-velocity relationship, increasing test velocities decreases the values generated for concentric forces. ${ }^{14-16)}$ Since archery is a rather static exercise requiring high concentric force at lower speed of shoulder movement, the data derived from measurement at $180^{\circ} / \mathrm{sec}$ angular velocity should not be considered for a more appropriate evaluation. Therefore, we interpret that the adduction peak torque on the left shoulder of archery athletes is greater than that of non-athletes, even though the value at $180^{\circ} / \mathrm{sec}$ angular velocity is statistically not different. We observed lower flexion peak torques and higher extension peak torques in the archery athletes than the non-athletic group; the difference is not considered negligible due to the borderline $p$-value, and we believe the difference would be statistically significant with an increased sample size.

These findings are closely associated with archery shooting and posture. Archery shooting consists of six segments, which include bow hold, drawing, full draw, aiming, release, and follow-through. During full draw and aiming phase, the archer maintains the posture for a few seconds; the shoulder muscles are mostly activate during this phase. For a stable posture, the drawing shoulder requires enough pulling strength to resist bending power of the bow. This could be the reason why extension peak torque of the drawing shoulder (right shoulder in this study) is greater in the archer group. Muscle activation of the bow shoulder is more complicated. The angle of the bow arm is slightly elevated and forward flexed against the line connecting both shoulders during full draw and aiming phase (Fig. 2). Because the bow arm is obliquely oriented towards the line of force made by the bow and string in both coronal and transverse planes, more extension and adduction shoulder power is required to stabilize the bow arm.

During athletics, the agonist muscles produce concentric work to accelerate the limb forward, whereas the antagonist muscles control or decelerate this concentric work, thereby preventing joint overloading. ${ }^{14,17-19)}$ In this study, we found that the peak torque ratios of flexion/extension of both shoulder girdle muscles at all angular velocities are significantly lower in the archery athletic group compared with the non-athletic group. This indicates that the shoulder extension strength of an elite archer is relatively stronger than the flexion strength. This can therefore be interpreted that the shoulder extensor muscles play an important role as primary antagonist to resist the force generated by bow and string. The flexor muscles act as a second antagonist

Table 3. Comparisons of Peak Torque Ratios of Shoulder Girdle Muscles in Archer and Control Group

\begin{tabular}{|c|c|c|c|c|c|c|}
\hline \multirow{2}{*}{ Variable } & \multicolumn{3}{|c|}{ Right } & \multicolumn{3}{|c|}{ Left } \\
\hline & Archer group & Control group & $p$-value & Archer group & Control group & $p$-value \\
\hline \multicolumn{7}{|l|}{$\mathrm{FL} / \mathrm{EX}$} \\
\hline $60^{\circ} / \mathrm{sec}$ & $51.84 \pm 11.23$ & $59.60 \pm 10.29$ & $0.018^{\star}$ & $49.39 \pm 8.65$ & $61.17 \pm 16.38$ & $0.014^{*}$ \\
\hline $120^{\circ} / \mathrm{sec}$ & $50.91 \pm 12.11$ & $58.40 \pm 7.91$ & $0.008^{*}$ & $45.59 \pm 10.15$ & $59.24 \pm 10.59$ & $0.001^{*}$ \\
\hline $180^{\circ} / \mathrm{sec}$ & $51.92 \pm 10.56$ & $62.61 \pm 12.20$ & $0.007^{*}$ & $47.96 \pm 12.13$ & $60.89 \pm 12.61$ & $0.005^{\star}$ \\
\hline \multicolumn{7}{|l|}{$\mathrm{ABD} / \mathrm{ADD}$} \\
\hline $60^{\circ} / \mathrm{sec}$ & $60.13 \pm 10.32$ & $58.82 \pm 13.50$ & 0.772 & $58.18 \pm 9.77$ & $57.63 \pm 16.96$ & 0.678 \\
\hline $120^{\circ} / \mathrm{sec}$ & $51.86 \pm 12.12$ & $58.42 \pm 12.28$ & 0.19 & $48.64 \pm 11.36$ & $59.37 \pm 13.90$ & $0.023^{*}$ \\
\hline $180^{\circ} / \mathrm{sec}$ & $54.77 \pm 11.24$ & $58.74 \pm 13.90$ & 0.32 & $47.21 \pm 13.55$ & $58.32 \pm 14.23$ & $0.027^{*}$ \\
\hline \multicolumn{7}{|l|}{ ER/IR } \\
\hline $60^{\circ} / \mathrm{sec}$ & $58.28 \pm 14.73$ & $62.35 \pm 10.76$ & 0.174 & $51.02 \pm 12.82$ & $58.50 \pm 14.89$ & 0.135 \\
\hline $120^{\circ} / \mathrm{sec}$ & $56.34 \pm 13.96$ & $60.68 \pm 11.30$ & 0.268 & $48.92 \pm 11.71$ & $56.55 \pm 11.43$ & 0.075 \\
\hline $180^{\circ} / \mathrm{sec}$ & $54.43 \pm 12.59$ & $63.34 \pm 10.06$ & $0.027^{*}$ & $46.68 \pm 12.06$ & $58.62 \pm 10.39$ & $0.005^{*}$ \\
\hline
\end{tabular}

Values are presented as mean \pm standard deviation.

Archer group: high level archery athletes, Control group: sex, age-matched healthy, non-athlete volunteers, FL/EX: flexion/extension ratio, ABD/ADD: abduction/adduction ratio, ER/IR: external rotation/internal rotation ratio.

${ }^{*} p<0.05$ with Mann-Whitney U-test. 


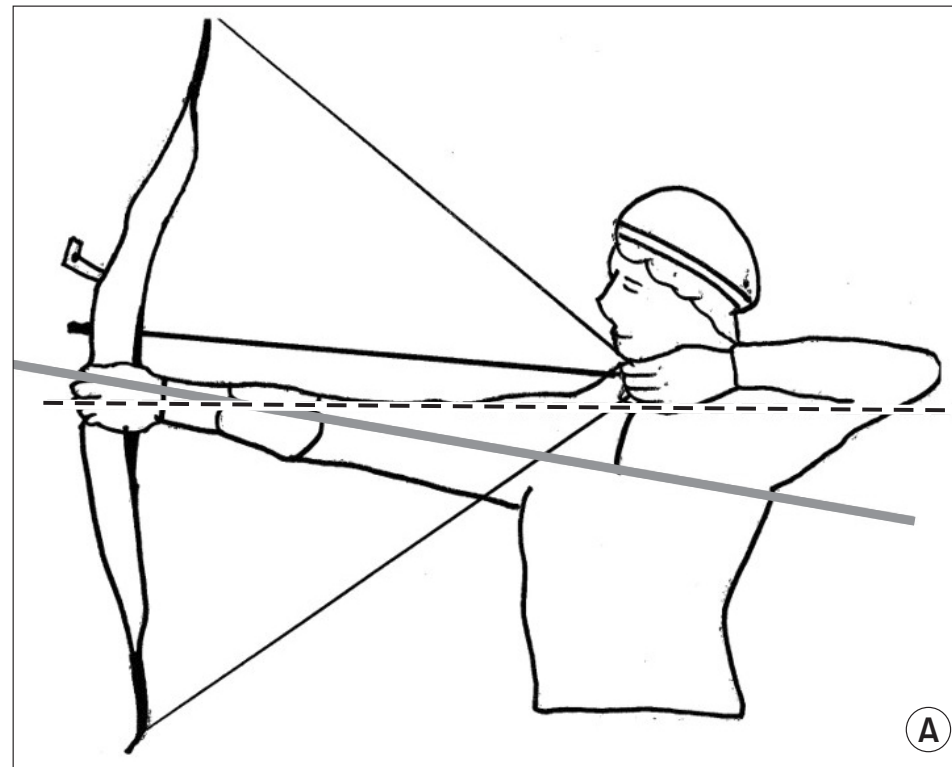

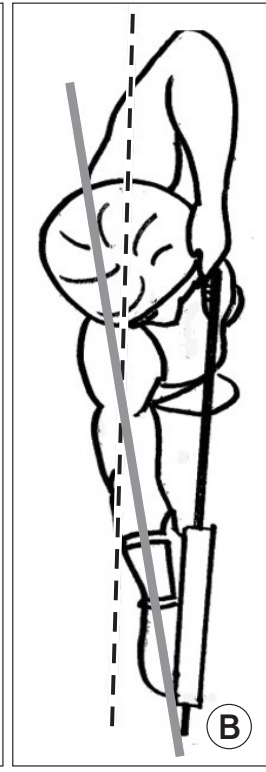

Fig. 2. Archery shooting posture at aiming phase. (A) On frontal plane, bow arm line (solid line) is slightly angled upward compared to shoulder line (dashed line). (B) On transverse plane, bow arm line (solid line) is slightly angled forward compared to shoulder line (dashed line). to the extensor muscles (agonist for force by bow and string) to control and stabilize the shoulder girdle in the drawing, aiming and release phases of archery shooting, regardless of the bow and drawing arm (Fig. 3).

Numerous studies have investigated the agonist/antagonist peak torque ratios, especially for the shoulder external rotation/ internal rotation. ${ }^{20-23)}$ The peak torque ratio of external rotation/ internal rotation is used as an indicator of predicting shoulder injury and monitoring the functional status during rehabilitation by assessing changes in the ratios. Mayer et al. ${ }^{24)}$ presented normal values for the general population for external rotation/internal rotation ratios as $60 \% \mathrm{sec}$; 0.57 for the dominant side and 0.61 for the non-dominant side. In our study, the peak torque ratio of external rotation/internal rotation at $60 \% \mathrm{sec}$ in the archery group is $58.3 \%(0.583)$ for dominant side and $51 \%(0.51)$ for non-dominant side, whereas ratio in the control group is $62.3 \%$ (0.623) for dominant side and 58.5\% (0.585) for non-dominant side. We observed no substantial difference between the two groups with respect to the peak torque ratios of external rotation/internal rotation.

There are several limitations in this study. First, inherent to all small sample size studies, the sample in each group might not be sufficiently powered to detect the differences between the two groups. Significant differences are observed only in comparison of peak torque ratios of flexion/extension in our study. However, with a larger sample size, additional characteristic feature could possibly be identified which would help distinguish elite archers from non-athletic individuals. Second, although this study is age and sex-matched, obvious differences exist between the two groups with respect to body weight and body muscle. This would affect the diversity of peak torque values obtained from each individual, and therefore interrupt an adequate analysis

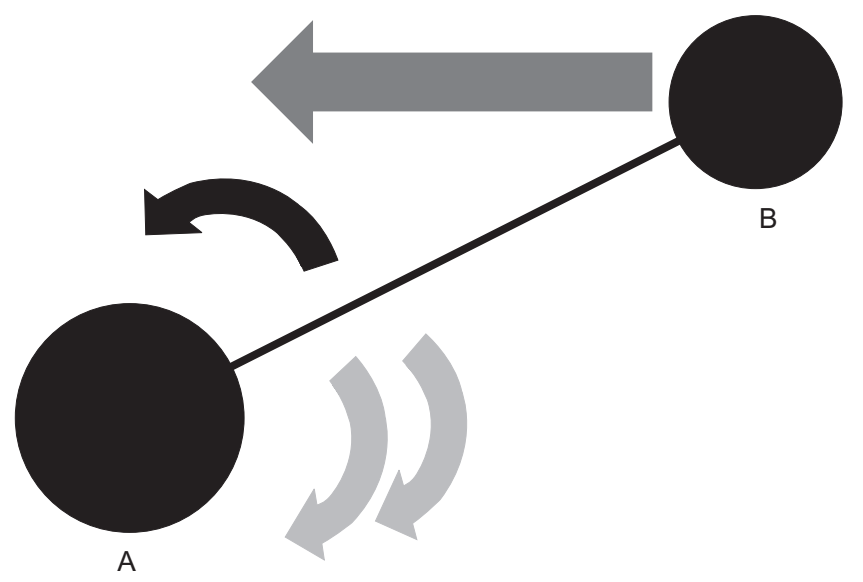

Fig. 3. Schematic drawing of agonist and antagonist muscles of bow shoulder at aiming phase during archery shooting. At aiming phase, bow arm (solid line between $A$ and $B$ ) should maintain its position. Therefore, the shoulder girdle (A) must be stabilized against force from hand (B). To stabilize the shoulder girdle, the shoulder muscle at the opposite side of force contracts as an antagonist whereas the shoulder muscle contracts as an agonist at same side. More antagonist force is required to stabilize the shoulder girdle (straight arrow, force from bow; black curve arrow, agonist muscle force; gray curved arrows, antagonist muscle force).

of isokinetic strength profile of the shoulder. Third, although an important component for archery athletes, muscle endurance was not investigated in this study. Finally, we did not assess the periscapular muscle activities because special attachments which are required to assess the periscapular muscle activity, were not available.

Although there are some limitations in this study, to the best of our knowledge this is the first study to analyze the isokinetic strength profile of the shoulders in an elite archery team. 


\section{Conclusion}

The prominent shoulder girdle muscle characteristic of an elite archer is stronger adductor muscle group on the bow shoulder and stronger extensor group on both shoulders, as compared to healthy, non-athletic individuals. These shoulder muscle groups possibly contribute a major role in maintaining the accuracy and stability during archery shooting. Therefore, a selective training program which enhances the adductor and extensor muscles might be helpful in enhancing archery performance.

\section{References}

1. Leroyer P, Van Hoecke J, Helal JN. Biomechanical study of the final push-pull in archery. J Sports Sci. 1993;11(1):63-9.

2. Mann DL, Littke N. Shoulder injuries in archery. Can J Sport Sci. 1989;14(2):85-92.

3. Clarys JP, Cabri J, Bollens E, et al. Muscular activity of different shooting distances, different release techniques, and different performance levels, with and without stabilizers, in target archery. J Sports Sci. 1990;8(3):235-57.

4. Ertan H. Muscular activation patterns of the bow arm in recurve archery. J Sci Med Sport. 2009;12(3):357-60.

5. Ertan $\mathrm{H}$, Kentel B, Tümer ST, Korkusuz F. Activation patterns in forearm muscles during archery shooting. Hum Mov Sci. 2003;22(1):37-45.

6. Ertan H, Soylu AR, Korkusuz F. Quantification the relationship between FITA scores and EMG skill indexes in archery. J Electromyogr Kinesiol. 2005;15(2):222-7.

7. Hennessy MP, Parker AW. Electromyography of arrow release in archery. Electromyogr Clin Neurophysiol. 1990;30(1):7-17.

8. Lin JJ, Hung CJ, Yang CC, Chen HY, Chou FC, Lu TW. Activation and tremor of the shoulder muscles to the demands of an archery task. J Sports Sci. 2010;28(4):415-21.

9. Bak K, Magnusson SP. Shoulder strength and range of motion in symptomatic and pain-free elite swimmers. Am J Sports Med. 1997;25(4):454-9.

10. Brown LP, Niehues SL, Harrah A, Yavorsky P, Hirshman HP. Upper extremity range of motion and isokinetic strength of the internal and external shoulder rotators in major league baseball players. Am J Sports Med. 1988;16(6):577-85.

11. Mikesky AE, Edwards JE, Wigglesworth JK, Kunkel S. ECcentric and concentric strength of the shoulder and arm musculature in collegiate baseball pitchers. Am J Sports Med. 1995;23(5):638-42.
12. McMaster WC, Long SC, Caiozzo VJ. Isokinetic torque imbalances in the rotator cuff of the elite water polo player. Am J Sports Med. 1991;19(1):72-5.

13. Andrade Mdos S, Fleury AM, de Lira CA, Dubas JP, da Silva AC. Profile of isokinetic eccentric-to-concentric strength ratios of shoulder rotator muscles in elite female team handball players. J Sports Sci. 2010;28(7):743-9.

14. Aagaard P, Simonsen EB, Magnusson SP, Larsson B, DyhrePoulsen P. A new concept for isokinetic hamstring: quadriceps muscle strength ratio. Am J Sports Med. 1998;26(2):231-7.

15. Aagaard P, Simonsen EB, Trolle M, Bangsbo J, Klausen K. Specificity of training velocity and training load on gains in isokinetic knee joint strength. Acta Physiol Scand. 1996;156(2):123-9.

16. Greenfield BH, Donatelli R, Wooden MJ, Wilkes J. Isokinetic evaluation of shoulder rotational strength between the plane of scapula and the frontal plane. Am J Sports Med. 1990;18(2): 124-8.

17. Glousman R, Jobe F, Tibone J, Moynes D, Antonelli D, Perry J. Dynamic electromyographic analysis of the throwing shoulder with glenohumeral instability. J Bone Joint Surg Am. 1988; 70(2):220-6.

18. Kronberg M, Németh $G$, Broström LA. Muscle activity and coordination in the normal shoulder. An electromyographic study. Clin Orthop Relat Res. 1990;(257):76-85.

19. Dillman CJ, Fleisig GS, Andrews JR. Biomechanics of pitching with emphasis upon shoulder kinematics. J Orthop Sports Phys Ther. 1993;18(2):402-8.

20. Burnham RS, May L, Nelson E, Steadward R, Reid DC. Shoulder pain in wheelchair athletes. The role of muscle imbalance. Am J Sports Med. 1993;21(2):238-42.

21. Leroux JL, Codine P, Thomas E, Pocholle M, Mailhe D, Blotman F. Isokinetic evaluation of rotational strength in normal shoulders and shoulders with impingement syndrome. Clin Orthop Relat Res. 1994;(304):108-15.

22. Wilk KE, Andrews JR, Arrigo CA, Keirns MA, Erber DJ. The strength characteristics of internal and external rotator muscles in professional baseball pitchers. Am J Sports Med. 1993;21(1):61-6.

23. Wang HK, Macfarlane A, Cochrane T. Isokinetic performance and shoulder mobility in elite volleyball athletes from the United Kingdom. Br J Sports Med. 2000;34(1):39-43.

24. Mayer F, Horstmann T, Röcker K, Heitkamp HC, Dickhuth $\mathrm{HH}$. Normal values of isokinetic maximum strength, the strength/velocity curve, and the angle at peak torque of all degrees of freedom in the shoulder. Int I Sports Med. 1994;15 Suppl 1:S19-25. 